\title{
Job evaluation as a mechanism for achieving the fairness of a wage structure in the administrative system: theoretical perspectives
}

\author{
Suzan Abd El Moneim El Balshy and Mamdouh Ismael \\ Public Administration, FEPS, Cairo, Egypt
}

\begin{abstract}
Purpose - This paper aims to present a theoretical framework which reveals the relationship between job evaluation (JE) and the development of fair wage structure from the organizational justice (OJ) perspective. It focuses on analyzing the dimensions of job-based pay structure and the use of multifaceted construct of OJ (procedures, distribution and interaction) to determine how the perceived justice of JE's multi-levels construct contributes to achieve the fairness of wage structure.

Design/methodology/approach - This paper adopts an analytical descriptive approach in terms of explaining the perspectives and viewpoints related to the analysis. This paper is based on examining a theoretical framework provided by the authors based on a theoretical review of literature and a set of empirical evidences.

Findings - The design of a hierarchical wage structure counts on the multidimensional approach of JE which consists of three dimensions (processes, outcomes and social system). In addition, the determination of wage structure fairness is dependent on the assessment of the perceived justice of: JE's procedures, wages distribution and management's treatment with its employees.

Originality/value - This study provides a new theoretical contribution in studying the relationship between $\mathrm{JE}$ and the design of fair wage structure. This contribution can be regarded as a theoretical foundation for conducting some empirical and comparative studies in the future. The study affords directive mechanisms to policymakers in order to enhance the fairness of the wage structure across the state.
\end{abstract}

Keywords Job evaluation, Wage structure, Fairness, Administrative system, Theoretical perspectives

Paper type Research paper

\section{Introduction}

$\mathrm{JE}$ is a systematic and consistent approach, which its main objective is to develop fair wage grades corresponding to consistent job levels. This objective is achieved by a set of sequent processes, fair distribution of monetary values between the similar jobs and employees' acceptance of the wage adjustment decisions. This multidimensional approach of developing a hierarchical wage structure requires enhancing "justice" across its different stages to achieve the fair wage based on the relative value of jobs among the employees performing the same job.

Although "justice" is important in developing a hierarchical wage structure, there is a scarcity of studies on employing OJ construct with its three main dimensions (distribution, procedures and interaction) in explaining the relationship between JE and the development of a fair wage structure. Most studies have discussed this relationship from some restricted theoretical perspectives. For example, a number of JE scholars (e.g. Dep, 2006; O’Riordan, 2008; Choudhary, 2016) have examined job-based pay from the "rationality" perspective. Their

(C) Suzan Abd El Moneim El Balshy and Mamdouh Ismael. Published in Journal of Humanities and Applied Social Sciences. Published by Emerald Publishing Limited. This article is published under the Creative Commons Attribution (CC BY 4.0) licence. Anyone may reproduce, distribute, translate and create derivative works of this article (for both commercial and non-commercial purposes), subject to full attribution to the original publication and authors. The full terms of this licence may be seen at http:// creativecommons.org/licences/by/4.0/legalcode

Job evaluation for a wage structure

Received 20 February 2021 Revised 18 May 2021 2 July 2021 26 July 2021 Accepted 26 July 2021

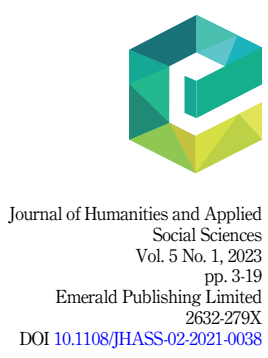


JHASS 5,1

analyses have revealed that the logical foundations of JE have given legitimacy for taking consistent decisions and judgments toward the determination of a fair wage. While El- Hajji's (2011) study findings have suggested the possibility of achieving the wage fairness in the context of JE scheme through both the internal and external "consistency" of wages. As for the field study of Jones et al. (1999), although they have indicated that pay increase is associated with the fairness of JE procedures, their analytical perspective was strictly limited as they have discussed JE as well as other practices related-pay (e.g. performance). Moreover, their study has lacked the theoretical conceptualization of JE in the context of procedural justice.

We, the authors, have argued that this is a worthy subject of research because it provides a conceptualization of multidimensional approach of job-based pay in the context of the three dimensions of OJ (procedural, distributive, interactional justice), which helps to determine the mechanisms required for designing a fair job and wage structure. Since it represents a new theoretical contribution for both JE and OJ literature, it will add value to JE literature (e.g. Armstrong and Baron, 1995; Armstrong and Murlis, 2007). Because it underpins the arguments advocating job-based pay, on one hand, and acts as an extension to the very small number of OJ literature, such as Jones et al. study (1999), on the other hand. This theoretical framework may be criticized or improved by scholars and by pursuing new avenues of inquiry. Besides, they may employ the suggested theoretical structure as a foundation for conducting further empirical and comparative studies in the future. Therefore, this contribution will fill in the theoretical gap in the public administration literature.

Accordingly, the purpose of this paper is to investigate the extent to which the OJ theory is used to explain the relationship between JE and the development of a fair wage structure. We have structured this paper in a way that achieves this objective as follows: we begin with the theoretical framework of the study followed by a section on examining the dilemma of developing a hierarchical wage structure. Thereafter, we have discussed the rational link between JE and the design of a consistent grading, on one hand, and fair wage structure in the view of multifaceted construct of OJ, on the other hand. Finally, it concludes with results, implications of the study and a future research agenda in light of the research points of the study.

The current study introduces a theoretical structure (Figure 1) reflecting the relationship between the two study variables in light of the analysis of the three dimensions of the OJ. We have built up our analysis based on the overviews of both JE's and OJ's scholars, results of justice studies and the justice theories relevant to the study objective.

\section{Research methodology}

In this study, the adopted research methodology is based on qualitative approach. This study uses an analytical descriptive approach to analyze the theoretical structure of both job-based pay and OJ theory in order to achieve the objective of the study. We have made a comprehensive review of the literature using the secondary data represented in academic articles, periodicals, books, reports and online resources to the following:

(1) Identify the structured processes of designing a hierarchical wage structure.

(2) Discuss the two opposing sides of scholars' debate against the traditional system of job-based pay in order to identify the extent to which this paper contributes to develop the arguments advocating JE technique.

(3) Examine the logical link between JE and the development of fair wage structure through the analysis of dimensionality of job-based pay in view of its rational framework and associated organizational implications, and the development of conceptualization of job-based pay through the use of multifaceted construct of OJ (procedures, distribution and interaction). 


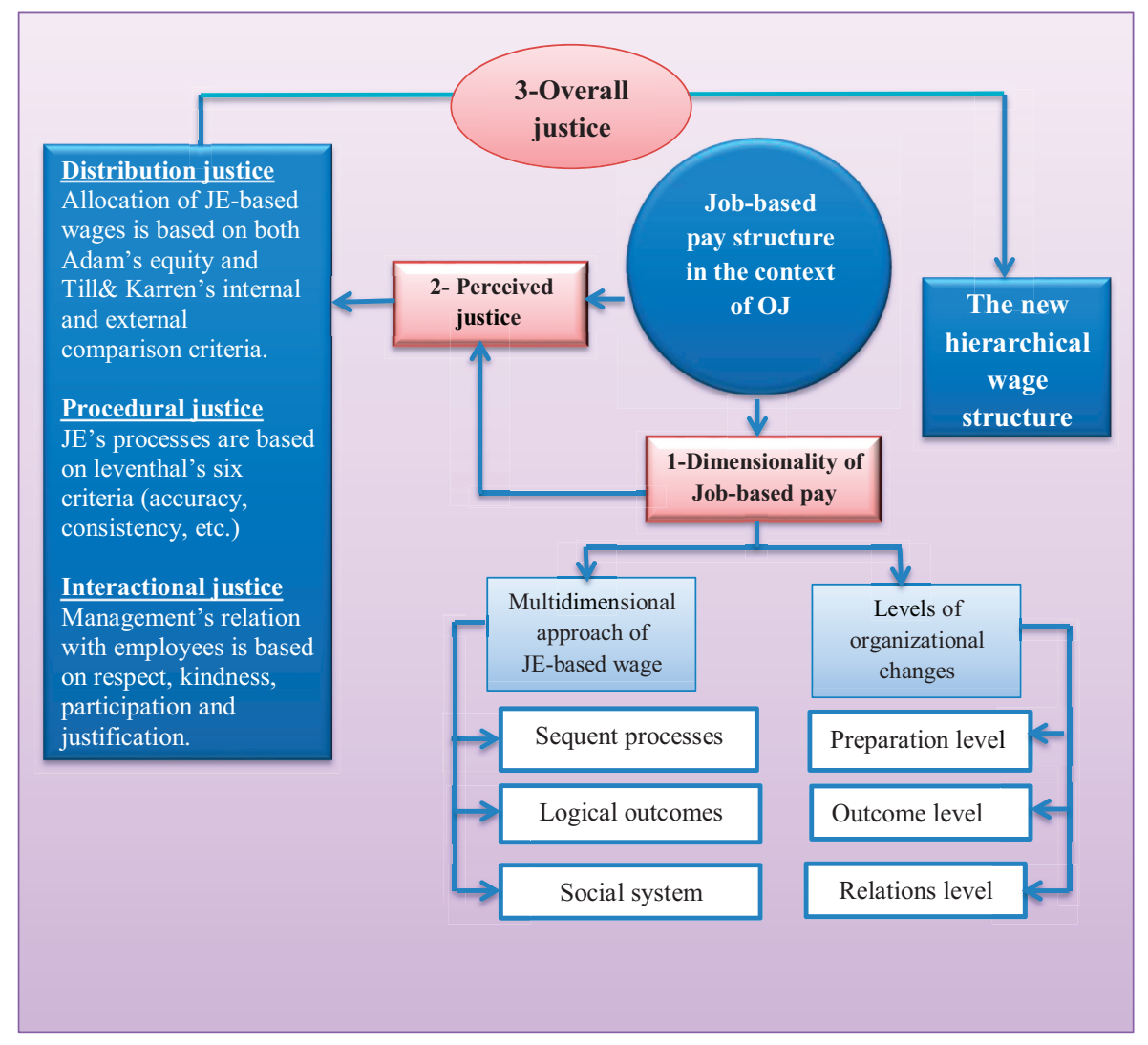

Source(s): Prepared by the researchers

\section{Theoretical framework of the study}

It addresses the definitions, systematic approach of JE and the administration of a hierarchical wage structure as follow:

\subsection{Concepts and definitions}

3.1.1 Definition of job evaluation. Some scholars have defined JE as the determination of job importance, or its relative weight, compared to other jobs. This could be attained by analyzing and describing jobs that clarify duties and responsibilities of a specific task or conditions, which should be met by a jobholder (Hashem, 1989, p. 314).

Furthermore, Omran (1997, p. 210) has focused on evaluating the quality of a job, or its relative worth, compared to other jobs in the organization through job analysis. This analysis has revealed the nature of the duties and responsibilities of the job and the conditions expected from those who are performing it.

Bose (2012, p. 245) has described JE as a methodological procedure for identifying the relative size of jobs within an organization and for establishing a consistent wage structure.

It can also be defined as "a process of identifying and measuring the factors (competencies), in each job, for which compensation is paid” (Eargle, 2013, p. 16). Another definition adopted by ILO (1982, p. 60) has made a similar assertion; whereas it is "a method of studying and grading jobs in order to provide a basis for a fair wage structure."
Job evaluation for a wage structure

Figure 1. Relationship between

JE and the development of a fair wage structure in the context of $\mathrm{OJ}$ construct 
JHASS 5,1

From our perspective, JE can be defined as a systematic process aims at determining the relative value of a job compared to others. This process depends on the results of the job analysis that produce both the job description and specification. As such, the difference in job values is counterbalanced by differences in wage levels.

3.1.2 Definition of a fair wage structure based on the relative value of jobs. We have attempted to develop the definition of a fair wage structure based on the relative worth of jobs by examining the following definitions:

3.1.2.1 Definition of a fair wage. According to Merriam-Webster Dictionary (2019), a fair wage is defined as "a wage that is reasonable for the type of work done." In the economics field, researchers consider wage rates to be fair in two aspects: the first takes the narrower perspective and when similar employees in the same industry receive wages equal to the current rate. Pigou (1985, p. 436) has embraced another aspect, which was related to the broader perspective and considered the wage rate to be fair when it is equal to the prevalent rate for similar work throughout the country and in the generality of trades.

In the administration field, researchers address the concept from the relative value perspective of the job compared to other jobs in order to achieve the internal justice. This assumes that the increase of wage rate from one grade to a higher one, in the wage scale, will be commensurated with the increase level in responsibilities and burdens added to the employee as a result of their transfer to a higher grade in the organizational structure (Al-Shehri, 2016, pp. 29-30).

Hence, a fair wage based on the relative value can be defined as the compensation an employee gets in exchange to the provisions of physical effort and mental power commensurately with the level of work difficulty, responsibilities and the skills required for performing the job expressed in monetary value; it includes two aspects, which are direct wages and other material on one hand and in-kind benefits on the other hand. Moreover, it is similar to the wage paid to the same work within and outside the organization.

3.1.2.2 Definition of wage structure. Researchers have agreed that wage structure represents the next step in job evaluation. This is because pay categories are identified according to the job hierarchy. Accordingly, it is defined as the sequence of jobs, in an orderly manner, based on the value of each job in relation to other jobs with specific pay rates, whereas, in the organization, jobs are arranged from the top to the bottom according to their relative importance. Consequently, wage rate is determined, separately, for each job (Hussnein, 2014, p. 89).

Armstrong (2007, p. 265) has defined wage structure as:

The different levels of pay for jobs or groups of jobs by referencing to their relative internal value as determined by job evaluation and to external relativities as established by market rate surveys. Sometimes to negotiate rates for jobs, they provide scope for pay progression in accordance with performance, competence, contribution or service.

Al-Khair and Al-Mikhlafi (2006) have pointed out that wage structure is related to the job pricing through identifying wage grades according to job levels in order to identify the monetary value representing the numerical value of the job.

From an analytical study of the above definitions, we may conclude a comprehensive definition of a fair wage structure based on the relative value as a determination of fair wage grades in relation to consistent job levels that are identified by its internal relative values based on JE. Thus, the incumbents of similar jobs receive similar wages-including direct wage and in-kind benefit-throughout the State.

\subsection{Systematic approach of JE: processes and implementation steps}

The systematic approach of JE will be discussed, in terms of highlighting its processes and implementation steps, as follows: 
3.2.1 Job evaluation processes. JE is an ongoing practice and it does not end at a particular stage. It must be systematic and well organized (Chaneta, 2014, p. 148). Additionally, it includes a set of consistent administrative schemes (Sharma, 2016, pp. 370-371):

(1) Job analysis: It identifies the duties, responsibilities, working conditions and roles of a job. Such information produce both job description and job specifications.

(2) Job rating: This includes assigning the relative score of each job in relation to other jobs and ranking their values.

(3) Money allocation: It is concerned with determining the money rate of wages to each job according to its relative size.

(4) Job classification: It involves grading different jobs into certain categories of scale of pay.

3.2.2 Implementation steps of job evaluation. Chaneta (2014, p. 148) has indicated that the application of JE as a management technique is dependent on four consistent implementation stages:

(1) Preparation: This stage involves the drafting of implementation program, selection of adequate methods and training of all the involved parties.

(2) Analysis and evaluation: This stage aims to announce the objective of JE and collect information before producing job descriptions.

(3) Developing wage structure: The design of the final wage structure is formulated based on the evolution and pricing of grades.

(4) Implementation and control: The management seeks to achieve a final agreement with the employees' representatives on the procedures required for implementing the suggested wage structure.

\subsection{Administration of a hierarchical wage structure: guiding principles and steps}

The design of a suggested/new wage structure, according to JE's systematic methodology, is based on two aspects:

3.3.1 Guiding principles of a hierarchical wage structure. Armstrong and Taylor (2017, p. 492) have suggested some guiding principles for designing a hierarchical wage structure, as it should:

(1) Simplify managing job and pay relativities.

(2) Enhance fairness, consistency and transparency in identifying the pay rates and managing both the job and wage structure.

(3) Allow jobs to be properly graded and not subjected to grade drift.

(4) Define the pay levels and the scope as required for pay progression.

(5) Enable the organizations to control the implementation of wage policies and budgets.

3.3.2 Steps of designing a hierarchical wage structure. Organizations use wage grades, which consists of jobs of equal value, grouped into grades with competitive salary ranges. Pay (or salary) ranges represent rates from the minimum to the maximum of each grade besides the midpoint, which represents the market value of the job. Once information is obtained from job analysis, JE and market analysis, there are several steps followed (Singer and Francisco, 2009, pp. 140-141).

(1) First: clustering jobs to set pay ranges. 
JHASS

5,1

8

(2) Second: calculating range spreads.

(3) Third: determining range progressions.

(4) Fourth: identifying the grades number and pointing difference between the grades.

(5) Fifth: costing the salary structure.

Generally, it is clear that designing a hierarchical wage structure depends on an objective, rational and standardized methodology of $J E$ that acts as a reasonable mechanism underpinning the fairness of wage structure through taking consistent decisions regarding the development of internally consistent job hierarchy and, accordingly, the determination of related wage grades.

\section{Dilemma of developing a wage structure based on the relative value of jobs}

Through the literature review, we have found much controversial debate, between both opponents and proponents against job-based pay. Their arguments have centered on four aspects as follows (as shown in Table 1).

Focus is the first point of difference, where performance-based pay rewards employee for the skills they possesses rather than the responsibilities of the job as a case in the traditional system, where the emphasis is on the employee's job title or grade (Baldwin, 2003, pp. 49, 77; Eargle, 2013, p. 128).

Arguably, the most fundamental reason for applying JE is to design an equitable and defensible wage structure. The proponent scholars (e.g. Armstrong and Baron, 1995; Armstrong and Murlis, 2007; El-Hajji, 2011) have settled on the advantages of JE as a rational and objective tool seeking to produce order out of chaos and establish the internal relativities of jobs based on consistent judgments. Moreover, it assists organizations to meet their legal and ethical obligations against the principle of "equal pay for work of equal value" by using the analytical schemes that facilitate frameworks to be designed in a way that underpins judgments on grading jobs and, therefore, pay rates.

However, the opponent scholars (Baldwin, 2003; Ledford, 1995) have advocated the newpay system as it intends to reinforce the organization's strategic goals and encourage the development of employees' skills and learning opportunities. Thus, base pay is identified according to the number of jobs individuals can perform.

Third, perhaps it is the most significant difference, it is the disadvantages of both systems; the advocating views of new pay model (e.g. Baldwin, 2003; Lawler, 1995; Eargle, 2013) have criticized JE to restrict individuals' duties and responsibilities to the job description;

\begin{tabular}{lll}
\hline Comparison elements & $\begin{array}{l}\text { Wage structure - based on the relative } \\
\text { value (Traditional system) }\end{array}$ & $\begin{array}{l}\text { Wage structure - based on } \\
\text { performance (New system) }\end{array}$ \\
\hline Focus & Job/Job content & $\begin{array}{l}\text { Skills and competencies of the job } \\
\text { holder } \\
\text { (1) Performance motivation }\end{array}$ \\
Advantages & $\begin{array}{l}\text { (1) Job security-order } \\
\text { (2) Consistency of wage structure } \\
\text { (3) Meeting ethical obligations }\end{array}$ & $\begin{array}{l}\text { (2) Meet modern organizations' } \\
\text { needs } \\
\text { (3) Lack of job security and } \\
\text { procedural justice } \\
\text { (1) Limited total rewards }\end{array}$ \\
Disadvantages & $\begin{array}{l}\text { (1) Subjectivity } \\
\text { (2) Bureaucratic approach } \\
\text { (3) Restricted individual's creativity } \\
\text { (4) Adherence to job description }\end{array}$ & Vertical \\
Hierarchical &
\end{tabular}

Table 1.

Traditional wage structure versus new wage structure

structure shape

Wage structure - based on the relative

(1) Job security-order

(2) Consistency of wage structure

(1) Subjectivity

Restricted individus

(4) Adherence to job description

Hierarchical

(s): Prepared by the researchers 
consequently, it limits individuals' creativity. They have argued that JE focuses on internal pay relations and works against strategic and competitive pay. In addition, JE can create undesirable power relationships in the organization. Furthermore, they have believed that the notion of paying, according to the job content, is an outmoded idea to pay in the context of market-oriented approach. Similarly, an empirical study (Maycock, 2009) has revealed that the new pay system also has disadvantages as it may reduce pay equity and include unfairness in the evaluation process due to the inaccurate measurements and managers' subjectivity. This indicates that employees are also being controlled via reward system.

Finally, compared to job-based pay, the new model is more adequate to the flatter organizations with fewer promotional levels while the traditional model promotes a bureaucratic approach that adheres to the organizational rigidity and hierarchy (as cited in Armstrong and Baron, 1995, p. 44).

Despite the preceding criticisms against job-based pay mode, it is still the most attractive mechanism for some governments that attempt to reform both their job and wage structures. For example, Egypt has recently taken a set of arrangements to reform the traditional approach of job-based pay model, which has been implemented by virtue of decision No. 134 of 1978 (Amin, 2019). Additionally, the head of Central Agency for Organization and Administration (hereinafter referred as CAOA, 2019b) has issued a decision No 35 of 2019. This decision aims at reviewing job description cards, evaluating jobs and job budget forms (Form No. 5) and studying the proposals introduced by the administrative units, whether to establish and re-evaluate jobs or to examine self-financing proposals for jobs at different levels (CAOA, 2019a). The traditional model of the Egyptian case focuses on the job titles (e.g. "floor supervisor," "clerk-typist," "machine operator") and assigns a pay scale to these jobs. Additionally, the wages of supervisory jobs, for example, may also take into account the number of employees being supervised. As for pay progression, it is based on the time spent on the job (Decision No. 35 of 2019). These characteristics are completely different from performance-based pay model, where pay levels are established on the basis of skills and knowledge required to perform the task and are higher compared to job-based pay (Baldwin, 2003).

With respect to the discussions mentioned earlier, we have observed that most scholars' discussions focused on JE's rationality and its main function on grading jobs within a grade structure and developing a consistent wage structure. Hitherto, no research has examined how the multidimensional construct of OJ contributes to underpin the "fairness" of a hierarchical wage structure. Accordingly, we hope our theoretical structure, which will be discussed in the following section, adds a value in this regard.

\section{Relationship between $\mathrm{JE}$ and the development of a fair wage structure in the context of $\mathrm{OJ}$ construct}

In this section, we provide a theoretical structure (Figure 1) that addresses the link between JE and the development of a fair wage structure from OJ perspective. This framework will be discussed through the analysis of the following aspects:

\subsection{Dimensionality of job-based pay}

We believe that the analysis of JE dimensionality structure will aid in determining whether the process of developing a hierarchical wage structure is a uni- or multi-dimensional. This examination will act as a basis for developing a conceptualization of the perceived justice toward a hierarchical wage structure. The items for this dimensionality will be generated by analyzing the seminal work in the JE literature relevant to both the rational framework of JE and its associated organizational implications.

5.1.1 Rational framework of job-based pay. Most of the management scholars view JE as a systematic and consistent approach underpinning the principle of "equal pay for work of equal value.” For example, Dep (2006, p. 285) has indicated that JE is a systematic approach of

Job evaluation for a wage structure 
JHASS 5,1

ordering jobs with regard to their relative size to the organization. In addition, it is a technique for obtaining job facts, analyzing jobs, preparing job description cards and conducting assessments and comparisons. Hence, it provides a reasonable basis for comparing the relative size of jobs; therefore, it defines their internal relativities of jobs and taking consistent decisions of grading jobs within a grade structure. In this context, Choudhary (2016, p. 92) have emphasized that these structured procedures aimed at studying the requirements of jobs and establishing a specific scope for their measurement to create a hierarchy of jobs.

Moreover, Quaid (1993, p. 223) has viewed JE as a rational process which is processed by rational people, who have developed rational and acceptable standards that allow rational results to be achieved. Therefore, this rational part of JE helps laying the rationale for addressing the wage's issues. In this framework, Armstrong and Baron (1995, pp. 16-17) have observed that organizations have taken initiatives to apply a JE technique in order to improve rational judgments rather than the political ones in assigning wages.

5.1.2 Associated organizational implications of developing a hierarchical wage structure. The implementation of JE technique has deep implications on the organization, such as the management's decision to objectively update or re-evaluate the job description, if it is inaccurate (Picardi, 2019, p. 110). Furthermore, Joffe (1989, p. 289) has demonstrated that JE's application has also a notable impact on changing the organizational structures relevant to grading structure and correcting relations among various jobs. He believed that a grade structure with defined point ranges represents a means for grading both new and changing jobs.

Within this framework, the organizations may take a decision either to develop a new grading structure, if the current one is discredited or out-of-date, or redesign the existing grading structure, if the existing one is formally established; sometimes as what takes place in the public sector (Armstrong and Baron, 1995, pp. 344-345).

Other scholars (O'Riordan, 2008; Joffe, 1989) have indicated that such consistent decisions, on grading jobs in the structure and setting pay rates, may influence the relationship between the managementand employees if they donotacceptand support these decisionsas fair and equitable.

Thus, the management decisions regarding wage grades modification may raise employees' concerns of perceived inequity in the new order. In this case, the organization should establish an agreed procedure to limit employees' grievances (Joffe, 1989, p. 285). Hence, the organization should determine, before the announcement of any initial results, how to deal with the employees' appeal (Dep, 2006, p. 287).

Based on the previous two analytical sides, we believe that JE is not a "one and done" activity. It is a multidimensional approach, which comprises of three integrated dimensions, as indicated in Figure 1:

(1) Sequent processes and steps: It refers to the implementation of JE.

(2) In conjunction with a group of administrative activities, such as collecting information, analyzing jobs, preparing job description cards and selecting JE's criteria. The veracity of every process is dependent on the accuracy of the preceding step.

(3) Logical outcomes: It indicates that the application of JE's processes and steps lead to some organizational consequences regarding establishing the internal relativities, grading jobs, identifying the range of job weight.

(4) The social system: It provides the context of human interaction between the management and employees that generates either the acceptance or objection of the management's decisions.

Furthermore, there is a group of organizational changes that are taken place across the different stages of developing a hierarchical wage structure. These changes may be classified into three levels corresponding to the three aforementioned dimensions, as shown in Figure 1 as such: 
(1) Preparation level: At this level, the management may take a decision to review or update an inaccurate job description.

(2) Outcomes level: The most notable changes that are correlated with JE implementation are correcting the complex relation between jobs and pricing jobs according to the new job levels.

(3) Relations level: It reflects the degree by which the management takes a set of arrangements to deal with the employees' appeal, such as providing them with opportunities to participate in the decision making process or establishing an approved mechanism for dealing with their complains.

\subsection{Conceptualization of job-based pay in the context of OJ construct}

The main objective of examining the $\mathrm{OJ}$ is to determine how the perceived justice of JE procedures, distribution of wages based on the relative value and the organizational communication between managers and employees, is formed. It also attempts to identify how the fairness of new wage structure, is assessed.

5.2.1 Content and multidimensionality of OJ. OJ concept has received a great attention from the management scholars. According to Baldwin (2006, p. 1), OJ is "the extent to which employee perceives workplace procedure, interactions and outcomes to be fair in nature." Scholars have studied two, three and even four dimensions of OJ in the literature. However, the current study depends on Greenberg's (1990) three-dimensional model, as follows:

5.2.1.1 Procedural justice. It refers to the perceived fairness of the allocation process (Cropanzano and Bagger, 2006, p. 590). Additionally, it focuses on the fairness of the decision process leading to a particular outcome, such as fair pay. The individuals' perception of procedural justice are likely to be promoted if they are given the chance to present evidence and voice their concerns before decisions are made (Baldwin, 2006, p. 2).

A significant body of studies (e.g. Greenberg, 1996; Thibaut and Walker, 1975; Leventhal, 1980) have indicated that providing control over the process and decision making by allowing the employees to participate in the design of reward system can produce a feeling of process justice even when the outcomes are not to their advantage. It focuses on an individual's cognitive map of events that precedes the distribution of rewards. In this setting, some empirical evidences have found a positive impact of procedural justice on determining fair pay (e.g. Cloutier and Vihuber, 2008; Jones et al., 1999; Folger and Konovsky, 1989).

Leventhal (1980) has determined six rules that may help individuals to perceive the fairness of decision process as such (pp. 25-35):

(1) Consistency rule: An individual's assessment to procedural fairness may be based on the consistent application of allocation procedures across individuals and over time.

(2) Bias-suppression rule: It is related to the degree in which decisions are based on facts not subjective feelings.

(3) Accuracy rule: It indicates the degree in which gathering information is accurate and up to date.

(4) Representativeness rule: It allows individuals to have opportunities to express their views before the decision is made.

(5) Correctability rule: It is related to the opportunity to revise and modify decisions.

(6) Ethicality rule: It indicates the decisions are not based on gender, age, etc., but on the ethical values. 
JHASS 5,1

Thus, based on the framework of job-based pay, the perceived justice of JE's procedures is concerned with one's perception of the JE's processes fairness regarding gathering information, analyzing and classifying jobs, selecting JE's criteria and rating jobs. Moreover, individuals may use the six criteria of Leventhal (1980), whether to make accurate, consistent and neutral decisions and represent all basic concerns of the affected parties or to assess if the JE's processes and practices are fair or unfair.

Additionally, according to the voice criteria, the perceived fairness toward JE's practices is likely to be also enhanced by providing employees the opportunities to express their views and voice their concerns before making decisions related to reviewing job description, redesigning jobs and modifying wage grades.

5.2.1.2 Distributive justice. It refers to the individual's perception that the rewards or resources are fair when distributed in accordance with certain criteria. These criteria may require sharing rewards equally or determining the rewards according to the contributions (Leventhal, 1980, p. 30). Scholars have identified several distributive rules of a social nature, such as equity (Adams, 1965), equality and need (Deutsch, 1975) or of a historical nature (As cited in Rutte and Messick, 1995, p. 245). In this study, we focus on the equity rule, which serves the study objective.

One of the most important theories within the distributive justice framed by Adams (1965) is the equity theory. According to his analysis, the equity theory focuses on fair exchange, where the individual gives the inputs (efforts, experiences, education, etc.) and receives the outcomes (pay, bonuses and recognition), which are considered the products of the exchange. He has revealed that an individual's perception of injustice is caused by psychological rather than objective considerations that negatively affect both the observed person and the reference person. In other words, an individual feels unfair when they inputs and/or results are in an obverse relation with the others' inputs and/or results. In this context, Baldwin (2006, p. 1) has stated that:

As it can be difficult for determining the level of reward for a particular degree of input, people tend to make this judgment in relative terms, looking for a contribution-outcome ratio that is similar to that of their peers.

Additionally, Till and Karren (2011, p. 43) have indicated that two types of equity (internal and external) comparisons are associated with individuals occupying the same job. Internal equity focuses on comparisons among individuals doing the same job inside the organization while external equity reflects comparisons among employees in an organization with those outside the same organization.

As far as we know, the effect of distributive justice perceptions regarding job-based pay is rarely been investigated. Hence, we depend on Greenberg's (1996) study findings, which revealed the possibility of applying equity theory to a range of elements. Based on this, the individuals' perception toward the distributive justice of the wages they receive, according to the relative size of their jobs, counts on the ratio of their relative value of jobs content (input)/wages (output) is equal to the ratios of their peers. In this case, the comparison criteria will be extended to involve the employees occupying the similar jobs inside and outside the organization as indicated by Till and Karren (2011). This comparison criterion is more adequate to the incumbents of similar jobs in the administrative systems, where some of these systems are still suffering from wage differential among employees occupying the same jobs, such as the Egyptian case - as discussed earlier.

Based on this, the perceived justice toward the distribution of job-based pay is dependent on the social comparison that represents an important source of information in which individuals rely on to decide the extent to which the distribution of wages among incumbents of similar jobs is fair. 
5.2.1.3 Interactional justice. Bies and Moag (1986) have introduced interactional justice as an independent dimension. It included the provision of information that explained the reasons beyond the outcomes as well as focusing on the human interaction between the presenter and receiver of justice. Moreover, it referred to the perceived fairness of interpersonal treatment that one receives. There are two correlated forms of this justice; first, the informational justice, which refers to the accuracy and clarity by which decision-makers justify events and explain decisions in details. Second, the interpersonal justice, which refers to the dignity and respect by which the individual is treated (Cropanzano and Bagger, 2006, p. 590). Both of these types were introduced as sub-parts of interactional justice. The fairness rules of the first type of justice are represented in justification and truthfulness, whereas the rules of the second type of justice are represented in respect and propriety (Colquitt, 2001; Greenberg, 1990).

Although there are few studies that have examined the impact of interactional justice on pay fairness, some empirical evidences have demonstrated that the confidence between the management and employees acts as a strong factor in achieving pay plans and systems (Léné, 2014; Ismail and Zakaria, 2009). Additionally, providing employees with adequate explanations and justifications has a positive influence on their behaviors (Ismail and Zakaria, 2009; Greenberg, 1993).

Generally, we agree with justice scholars' views that employees' approval of justicebased evaluations often meet their psychological needs, such as respect, self-esteem and belonging (Barclay and Kiefer, 2014; Rupp, 2011). Hence, employees' acceptance of the final wage structure depends on how far the individuals are treated respectfully, and whether they receive adequate explanations or justifications for decisions taken by their management, particularly, those related to wage grades modification. Additionally, this insight is aligned with JE scholars' viewpoints (e.g. Joffe, 1989; Dep, 2006), which clarifies that the absence of communication between the management and employees may raise the concerns regarding perceived inequity. Accordingly, the interactional justice, with its both types (informational and interpersonal), is considered as a requirement for applying a final wage structure.

5.2.2 Overall justice. Some empirical studies have addressed the relationship between each type of justice and a broad range of individuals' attitudes. For example, Colquitt et al. (2001) have clarified that work performance is mainly related to perceived procedural justice.

Whereas other justice scholars (e.g. Goldman and Cropanzano, 2014; Ambrose and Schminke, 2009; Greenberg, 2001; Shapiro, 2001) have criticized the exclusive focus on specific types of justice.

They believed that the focus on specific dimensions of the construct does not reflect the depth of an individual's experience of justice. As a result, they have called for the overall justice which is defined as "A global evaluation of the fairness of an entity based on personal experiences as well as on the experiences of others" (Holtz and Harold, 2009, p. 1185). They have demonstrated that overall justice provides an accurate and complete picture of how individuals make fair judgments.

Following this aspect, Eib (2015, p. 10) has indicated that overall justice is preferred over justice dimensions when the goal is to appraise broad outcomes (e.g. health, job satisfaction). He has postulated, "General impressions of justice are relatively stable and may only change when justice-relevant information is drastically inconsistent with the general impression." The findings of some empirical researches (Ambrose and Schminke, 2009; Beugre and Baron, 2001) have supported this ideology; they found that the combination of two or three dimensions of OJ are strong predictors of overall justice perception.

Furthermore, a group of justice scholars (Ambrose and Schminke's, 2009; Shapiro, 2001) have discussed an overall justice influence on organizational phenomenon. They have demonstrated that overall justice has a positive impact on outcomes and plays a mediating role between justice dimensions and outcomes including organizational commitment and job performance.
Job evaluation for a wage structure 
JHASS 5,1

Concerning the evaluative perceptions of overall justice, some scholars (Van den Bos, 2001; Lind, 2001) have used the "Fairness Heuristic Theory" to introduce an explanation to how employees form their perception toward overall justice. According to their analysis, the amount of information, available to employees, enable them to make conscious assessment of fairness. Even in the case of insufficient or less relevant information, individuals use other information, whether related to procedural or outcomes, to assess what is fair. In other words, people use available justice information to form their fair impression of outcomes.

According to the preceding analysis, we believe that the concentration on a particular dimension of determining the wage structure fairness based on the relative worth or size of jobs - as a different independent practice - may lead to embarrassing outcomes. As for the overall justice assessment the general assessment (e.g. Eib, 2015; Beugre and Baron, 2001; Shapiro, 2001), according to the information availability (Van den bos, 2001; Lind, 2001), regarding JE's procedures and wage distribution among similar jobs, it will produce a holistic and accurate judgments toward the hierarchical wage structure fairness. These general justice experiences may act as a mediating role (Ambrose and Schminke, 2009; Shapiro, 2001) between the perceived justice of JE's procedures, the distribution of job-based pay and the human interaction between the managers and employees on one hand, and the acceptance of a new wage structure as a fair organizational outcome on the other hand (see Figure 1).

\section{Findings, recommendations and future research agenda \\ 6.1 Conclusion}

The current research has examined the relationship between JE and the development of a fair wage structure by developing a comprehensive definition of fair wage structure based on the relative worth of jobs. Moreover, it has discussed the methodological foundations for identifying the internal relativities of jobs, establishing consistent job levels and designing a hierarchical wage structure. In this paper, we have examined the insights and discussions raised by management scholars toward both traditional and new pay systems to determine to what extent the study findings contribute to the current debate. Finally, we have used OJ theory and other related intellectual perspectives of both JE's and OJ's scholars to develop an understanding of how the JE multidimensional approach underpins the "fairness" in designing a wage structure.

\subsection{Findings}

Results demonstrate that JE, as a management technique, seeks to manage the internal relativities of jobs and identify pay rates based on rational judgments. It is not a "one and done" activity. As it correlates with a set of administrative schemes (e.g. collecting information, job description, rating the jobs), which by turn, represents the input of JE.

Moreover, results indicate that the proponents of job-based pay model have adopted, basically, the "rationality" rather than the "fairness" perspective in their advocate. They view $\mathrm{JE}$ as a an effective mechanism for, rationally, fixing wages by using a logical method, which relies on a set of reasonable rules leading to make consistent decisions on grading jobs, accordingly, set pay rates.

Additionally, results emphasize that although the traditional system of job-based pay is still an area of confusion among management scholars, some governments (e.g. Egypt) has, recently, intended to re-evaluate its existing traditional approach of $\mathrm{JE}$ as a valuable tool dealing with the issues of wage disparity among employees in the similar jobs.

Results point out that the significant stands of the scholars' arguments, against both the traditional and new pay systems, have focused on four main elements related to focus, advantages, disadvantages and organizational shape. Accordingly, the present study adds a new aspect of discussion among the scholars. This aspect is related to the use of OJ construct in developing a fair wage structure. 
Results suggest that the perceived justice toward the development of a fair hierarchical wage structure composes of the following three components:

(1) Dimensionality of job-based pay: It refers to multi-levels construct of JE that consists of three main dimensions, namely, sequent processes, logical outcomes and social system. These three dimensions represent the pivotal foundations for whether developing a new grading structure or redesigning an existing one. Each dimension is affiliated with a set of organizational implications. This means that there are three levels of changes (preparation, outcome and relation), which are parallel to JE's dimensions, as shown in Figure 1.

(2) Perceived justice of job-based pay: It indicates the conceptualization of job-based pay in the context of the multifaceted construct of OJ, as such:

- Procedural justice of job-based pay: It is concerned with the enhancement of an individual's perception of JE's practices fairness (e.g. collecting information, preparing job description, identifying job-related scores) that leads to the determination of fair wage. This perception may be assessed via the use of Leventhal's six criteria, as follows:

- Consistency: It refers to the need for determining the relative and monetary values and pay ranges of similar jobs in a similar way.

- Bias suppression: It requires the raters objectivity and the application of JE technique, which should be based on facts not gender nor any subjective preferences, such as evaluating jobs according to gender occupying these jobs (direct bias) or making JE's judgments according to the discriminatory of current wages (indirect bias).

- Accuracy: It is related to the accuracy of information relevant to JE's policies and practices, such as those related to job analysis and description. It should reflect the reality and be up to date to take decisions correctly.

- Representativeness: It refers to the capacity of the organization to represent employees' concerns of wage adjustment, for instance, within the executive committees and JE units.

- Correctability: The organization's tendency to revise and evaluate the employees' complaints and grievances to make equitable decisions about re-assigning job-linked scores, redesigning jobs and modifying wage grades.

- Ethicality: The compatibility of decisions, which are related to the assignment of jobs' numerical and monetary values on one side and moral and ethical values, on the other side, regardless the age, gender, etc.

- Distributive justice of job-based pay: It seeks to employ the equity rule (Adams, 1965) to form the individuals' perception against job-based pay. This will be through providing them with information related to their peers' wages in order to compare their wage (outcome)/relative value of job content (input) ratio with other employees' ratio (referents), who occupy the same jobs with the same skills inside and outside the organization.

- Interactional justice of job-based pay: It reveals that the management can administer employees' grievances and objections toward its decisions relevant to wage grade modification, particularly the downgrades case, through employees'

Job evaluation for a wage structure

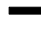


JHASS

5,1

16 participation in decision making, treating them with respect and providing them with adequate justifications as well as sufficient information.

(3) Overall justice toward the hierarchical wage structure: It indicates that evaluative perceptions against the final wage structure draws on the inclusive assessment of JE's procedural, money values' distributive and human interaction mechanism. This means that the available justice information, of two or three preceding dimensions, will provide more accurate and complete overview than the focus on a particular dimension.

Hence, the study suggests that a formulation of general justice experiences will act as mediation for determining whether the new wage structure is fair or unfair.

Based on aforementioned results, we believe that promoting "fairness" of job-based pay has the potential to address the different wage issues in the administrative systems. The success of achieving this objective depends on the degree of adherence to normal standards or fairness rules of job-based pay relating to procedures, distribution and organizational interaction.

\subsection{Recommendations}

We believe that a development of a fair wage structure at government entities, may achieve a set of advantages, such as the achievement of wage fairness between similar jobs, the governments' ability to control the wage costs and the public satisfaction and confidence toward the government policies. Therefore, we provide some recommendations as a valuable input to the Policy-makers, executive managers and HR practitioners, who are involved in job and wage structure reforms, as follows:

Policymakers have to formulate the guiding and legal frameworks of applying JE in a way that enhances the fairness, transparency and objectivity of the practices related to collecting information, conducting interviews, preparing job description cards, identifying job-related scores, redesigning jobs and dealing with upgraded and downgraded jobs, employees' complaints and transferring to equivalent grades. In addition, building an institutional and human capacity will provide both public bodies and employees with skills and tools that enable them to share information about JE's processes and its outcomes.

Additionally, they have to face the challenges concerning confidential policies of wage and take further arrangements in order to promote the policy of information disclosure in this regard. Furthermore, practitioners should pay specific attention to develop the interactive communication tools between the different stakeholders and knowledge sharing with employees on a regular basis.

Moreover, the establishment of a department for following and monitoring is a vital mechanism for ensuring the compliance of ministries, government agencies and JE units, with guiding and fairness rules. Furthermore, it ensures the conformity to the normative standards across all stages of developing a hierarchical wage structure.

Finally, our results suggest the use of the fairness standards in a way that underpins implementing consistent, accurate, objective policies and practices of job-based pay, on one hand, and reinforce both the employees' access to the information and participation in the decision making, on the other hand. This, in its turn, will assist the practitioners to assess their practices and conduct benchmarking practices.

Accordingly, taking such arrangements will reflect positively on employees' attitudes and satisfaction level; they will understand the logic behind conducting some organizational changes and taking the decisions of adjusting wage grades. Therefore, they will be able to formulate their comprehensive assessment toward the fair wage they receive.

\subsection{Future research agenda}

Conclusively, we, the authors, recommend some further researches related to the topic researched, such as the use of the proposed theoretical structure to make comparative studies 
between the traditional and the new pay systems. In addition, further researches, about assessing the fairness of a hierarchical wage structure of the single international practices between the developing and developed countries can be done.
Job evaluation for a wage structure

\section{References}

Adams, J.S. (1965), "Inequity in social exchange", in Berkowitz, L. (Ed.), Advances in Experimental Social Psychology, Vol. 2, Academic Press, New York, pp. 267-299.

Al-Khair, A.T. and Al-Mikhlafi, A.W. (2006), "The scientific foundations for achieving justice in job wage structures", Tishreen University Journal for Scientific Research and Studies, Vol. 28 No. 2 , pp. 3-20.

Al-Shehri, M.E. (2016), Salaries and Wages Administration, Institute of Public Administration, Riyadh.

Ambrose, L.M. and Schminke, M. (2009), "The role of overall justice judgments in organizational justice research: a test of mediation", Journal of Applied Psychology, Vol. 94 No. 2, pp. 491-500.

Amin, E. (2019), "An international perspective of job grading in the Egyptian administrative system", Review of Economics and Political Science.

Armstrong, M. (2007), A Handbook of Employee Reward Management and Practice, 2nd ed., Kogan Page, London.

Armstrong, M. and Baron, A. (1995), The Job Evaluation Handbook, 1st ed., CIPD Publishing, London.

Armstrong, M. and Murlis, H. (2007), Reward Management: A Handbook of Remuneration Strategy and Practice, 5th ed., Kogan Page, London.

Armstrong, M. and Taylor, S. (2017), Armstrong's Handbook of Human Resource Management Practice, 14th ed., Kogan Page Publishers, New York.

Baldwin, D.A. (2003), The Library Compensation Handbook: A Guide for Administrators, Librarian and Staff, Libraries Unlimited, Westport.

Baldwin, S. (2006), "Organizational justice, institute of employment", available at: https://www. employment-studies.co.uk/system/files/resources/files/mp73.pdf (accessed 22 August 2020).

Barclay, J.L. and Kiefer, T. (2014), "Approach or avoid? Exploring overall justice and the differential effects of positive and negative emotions", Journal of Management, available at: file:///C:/Users/ nour/AppData/Local/Temp/barclayandkieferJoMinpress.pdf (accessed 7 May 2020).

Beugre, C.D. and Baron, R.A. (2001), "Perceptions of systemic justice: the effects of distributive, procedural, and interactional justice", Joumal of Applied Social Psychology, Vol. 31 No. 2, pp. 324-339.

Bies, R.J. and Moag, J.F. (1986), "Interactional justice: communication criteria of fairness", in Lewicki, R.J., Sheppard, B.H. and Bazerman, M.H. (Eds), Research on Negotiation in Organizations, JAI Press, Greenwich, CT, Vol. 1, pp. 43-55.

Bose, D.C. (2012), Principles of Management and Administration, 2nd ed., PHI Private Learning, New Delhi.

CAOA (2019a), "Job grading”, available at: http://www.caoa.gov.eg/WebForms/ContentPages.aspx? Vu2z2OiuNisTYC61MG92Sj1Y/s5/mQYEBBJlmQbeF5Q (accessed 6 June 2019).

CAOA (2019b), "Decision No35 of 2019", available at: http://www.caoa.gov.eg/App_Files/Uploads/ Attachments/1558519941.pdf (accessed 28 April 2021).

Chaneta, I. (2014), "Effects of job evaluation on decisions involving pay equity", Asian Social Science, Vol. 10 No. 4, pp. 145-152.

Choudhary, S. (2016), "Job evaluation: a strategy for compensation consistency", International Journal of Advanced Research in Management and Social Sciences, Vol. 5 No. 5, pp. 90-100.

Cloutier, J. and Vihuber, L. (2008), "Procedural justice criteria in salary determination", Journal of Managerial Psychology, Vol. 23 No. 6, pp. 713-740.

Colquitt, J.A. (2001), "On the dimensionality of organizational justice: a construct validation of a measure", Journal of Applied Psychology, Vol. 86 No. 3, pp. 386-400. 
JHASS 5,1

Colquitt, J.A., Conlon, D.E., Wesson, M.J., Porter, C.O.L.H. and Ng, K.Y. (2001), "Justice at the millennium: a meta-analytic review of 25 years of organizational justice research", Journal of Applied Psychology, Vol. 86 No. 3, pp. 425-445.

Cropanzano, R. and Bagger, J. (2006), "Organizational justice”, in Greenhaus, J.H. and Callanan, G.A. (Eds), Encyclopedia of Career Development, Sage Publication, Thousand Oaks, CA, Vol. 1, pp. 590-591.

Dep, T. (2006), Strategic Approach to Human Resource Management: Concept, Tools, and Application, Atlantic Publishers and Distributers, New Delhi.

Deutsch, M. (1975), "Equity, equality, and need: what determines which value will be used as the basis of distributive justice?”, Journal of Social Issues, Vol. 31 No. 3, pp. 137-149.

Eargle, F.L. (2013), Job Evaluation: Traditional Approaches and Emerging Technology, 1st ed., Lulu.Com, Abu Dhabi.

Eib, C. (2015), "Process of organizational justice: insights into the perception and enactment of justice", Stockholm University, available at: http://www.diva-portal.org/smash/get/diva2:789976/ FULLTEXT01.pdf (accessed 27 September 2020).

El-Hajji, M.A. (2011), "Wage consistency in the context of job evaluation: an analytical view", International Journal of Business and Social Science, Vol. 2 No. 10, pp. 31-37.

Folger, R. and Konovsky, M.A. (1989), "Effects of procedural and distributive justice on reactions to pay raise decisions", Academy of Management Journal, Vol. 32 No. 1, pp. 115-131.

Goldman, B. and Cropanzano, R. (2014), “Justice' and 'fairness' are not the same thing”, Journal of Organizational Behavior, Vol. 36 No. 2, pp. 313-318.

Greenberg, J. (1990), “Organizational justice: yesterday, today, and tomorrow”, Journal of Management, Vol. 16, pp. 399-432.

Greenberg, J. (1993), "The social side of fairness: interpersonal and informational classes of organizational justice”, in Cropanzano, R. (Ed.), Justice in the Workplace: Approaching Fairness in Human Resource Management, Lawrence Erlbaum Associates, Hillsdale, NJ, pp. 79-103.

Greenberg, J. (1996), The Quest for Job Justice on the Job, Sage, Thousand Oaks, CA.

Greenberg, J. (2001), "Setting the justice agenda: seven unanswered questions about 'what, why, and how", Journal of Vocational Behavior, Vol. 58, pp. 210-219.

Hashem, Z.M. (1989), Human Resources Management, That Al Salasil for Printing, Publishing and Distribution, Al-Kuwait.

Holtz, B.C. and Harold, C.M. (2009), "Fair today, fair tomorrow? A longitudinal investigation of overall justice perception", Journal of Applied Psychology, Vol. 94 No. 5, pp. 1185-1199.

Hussnein, A.Gh. (2014), Administrative Frustration (Causes - Treatment), Arab Group for Training and Publishing, Cairo.

ILO (1982), Wages, A Workers Education Manual, 3rd ed., ILO, Geneva.

Ismail, A. and Zakaria, N. (2009), "Relationship between interactional justice and pay for performance as an antecedent of job satisfaction: an empirical study in Malaysia”, International Journal of Business and Management, Vol. 4 No. 3, pp. 190-199.

Joffe, B. (1989), The Impact of Job Evaluation in Large Local Authorities, Master of Arts in Sociology, University of Cape Town, Cape Town.

Jones, F.F., Scarpello, V. and Bergmann, T. (1999), "Pay procedures-what makes them fair?", Journal of Occupational and Organizational Psychology, Vol. 72 No. 2, pp. 129-145.

Lawler, E. (1995), “The new pay: a strategic approach", Compensation and Benefits Review, JulyAugust, pp. 14-22.

Léné, A. (2014), "Skill-based pay in practice: an interactional justice perspective", European Journal of Training and Development, Vol. 38 No. 7, pp. 628-641.

Ledford, G.E. Jr (1995), "Paying for the skills, knowledge, and competencies of knowledge workers", Compensation and Benefits Review, Vol. 27, pp. 55-62. 
Leventhal, G.S. (1980), "What should Be done with equity theory”, in Gergen, K.J., Greenberg, M.S. and Willis, R.H. (Eds), Social Exchange: Advances in Theory and Research, Plenium, New-York, Vol. 2012, pp. 1-55.

Lind, E.A. (2001), "Fairness heuristics theory: justice judgments as pivotal cognitions in organizational relations", in Greenberg, J. and Cropanzano, R. (Eds), Advances in Organizational Justice, Stanford University Press, Stanford, CA, pp. 56-88.

Maykock, E. (2009), "An investigation into performance based pay in Nigerian Financial Institutions", $\mathrm{Ph} . \mathrm{D}$ Thesis of Philosophy, University of Bedfordshire, Bedfordshire.

Merriam-Webster Dictionary (2019), "Fair wage", available at: https://www.merriam.com/dictionary/ fair\%20wag (accessed 5 April 2019).

Omran, K.M. (1997), Human Resources Management, Dar Kareem for Printing, Cairo.

O'Riordan, J. (2008), "A review of the civil service grading and pay system", Institute of Public Administration, available at: https://www.ipa.ie/_fileUpload/Documents/CPMR_DP_38_ Review_ofthe_Civil_Service_Grading_Pay_System.pdf (accessed 20 September 2019).

Picardi, C.A. (2019), Recruitment and Selection: Strategies to Workforce Planning and Assessment, Sage Publications, London.

Pigou, A.C. (1985), "Fair wage", in Ghodke, N.B. (Ed.), Encyclopedic Dictionary of Economics, Miltal Publications, New Delhi, p. 436, 1.

Quaid, M. (1993), “Job evaluation as institutional myth”, Journal of Management Studies, Vol. 30 No. 2, pp. 239-260.

Rupp, D.E. (2011), "An employee-centered model of organizational justice and social responsibility", Organizational Psychology Review, Vol. 1, pp. 72-94.

Rutte, C.G. and Messick, D.M. (1995), "An integrated model of perceived unfairness in organizations", Social Justice Research, Vol. 8 No. 3, pp. 239-261.

Shapiro, D. (2001), "The death of justice theory is likely if theorists neglect the wheels already invented and the voices of injustice victims", Journal of Vocational Behavior, Vol. 58 No. 2, pp. 235-242.

Sharma, R.C. (2016), Industrial Relations and Labour Legislation, PHI Learning Private, New Delhi.

Singer, P.M. and Francisco, L.L. (2009), Developing a Compensation Plan for Your Library, 2nd ed., American Library Association, Chicago.

Thibaut and Walker, L. (1975), Procedural Justice: A Psychological Analysis, Erlbaum, Hillsdale, NJ.

Till, E. and Karren, R. (2011), "Organizational justice perceptions and pay level satisfaction”, Journal of Managerial Psychology, Vol. 25 No. 1, pp. 42-57.

Van den Bos, K. (2001), "Fairness heuristic theory: assessing the information to which people are reacting has a positive role in understanding organizational justice", in Gilliland, S., Steiner, D. and Sharlicki, D. (Eds), Theoretical and Cultural Perspectives on Organizational Justice, A Volume in Research in Social Issues in Management, Information Age Publishing, Greenwich, pp. $63-84$.

\section{Corresponding author}

Suzan Abd El Moneim El Balshy can be contacted at: elbalshysuzan@gmail.com

For instructions on how to order reprints of this article, please visit our website:

www.emeraldgrouppublishing.com/licensing/reprints.htm

Or contact us for further details: permissions@emeraldinsight.com 